Brit. J. industr. Med., 1962, 19, 236.

\title{
A DUST DISPERSAL MACHINE FOR INHALATION EXPERIMENTS
}

\author{
BY \\ A. M. FISHER and HELEN CHRISTIE \\ From the Department of Physiological Hygiene, University of Toronto
}

(RECEIVED FOR PUBLICATION DECEMBER 10, 1961)

\begin{abstract}
A machine is described that permits the controllable production of dusty atmospheres in which experimental animals may be exposed for extended periods. This is accomplished by diluting the dust with dense inert material from which it is subsequently removed without involving changes in the particle size or physical nature of the dust which it is desired to suspend in the atmosphere.
\end{abstract}

In the study of long-term effects of exposure of laboratory animals to dusty atmospheres, an essential piece of equipment is a machine for providing controlled dispersal of dust of small particle size. It is desirable that the machine be one which will produce dusty atmospheres of reasonably constant composition variable over a wide range of dust counts. Air volume, air movement, and other conditions should be such that animals can be maintained in the experimental state for many months. The machine should be suitable for use with dusts obtained from industrial operations, for example, dusts from dust chambers and similar samples of very fine dusts, and should provide dust concentrations of the order of about fifty million particles per cubic foot (m.p.p.cu.ft.). This paper describes a machine meeting these requirements. It delivers a controlled dose of relatively small amounts of dust having a particle size of that of the original sample, uniformly throughout extended periods. Controlled dispersal of small amounts of fine dust is accomplished by dilution of the dust with a dense inert material from which it is subsequently removed by a continuous upward stream of compressed air.

The dust dispersal machine is shown in Fig. 1. Its essential features are a pressure gauge and pressure reducing valve to control the supply of fresh compressed air used in the equipment and subsequently piped to the exposure chambers, a group of five rotameters for measurement of air flow with control valves below them, two variable speed gear boxes, one on the left controlling the rotation of a mixing drum in which the dust and diluent are placed and one on the right controlling a screw which removes at uniform rate samples of dust and diluent from the mixing drum. The copper tubes on the lower part of the equipment are, on the left, a controlled supply of compressed air delivered from the reducing valve and, on the right, an air elutriation tube for removing by a continuous upward stream of air the dust from the mixture of dust and diluent delivered to it by the screw through the sloping copper tube.

The dust-free or almost dust-free diluent is collected in a flask (not shown) near the base of the elutriation tube for subsequent re-use, and the dusty air is delivered through the larger copper tube to rotameters for measurement of air volume or for dilution with dust-free air. As used in our laboratory for the past four years, dusty air from one dust dispersal machine is delivered to each of six exposure chambers in sequence through electrically operated valves controlled by an interval timer. A convenient schedule has been 20 seconds of air supply to each of six chambers in sequence through each two-minute cycle.

For exposure chambers we have found it convenient to use oven liners constructed for ordinary domestic electric stoves. Those at present in use measure $16 \times 23 \times 17$ in. and are suitable for housing as many as 12 rats or for receiving an auxiliary cage containing other animals, such as mice or birds, as shown in Fig. 2. When animals are being exposed to the dusty atmosphere the front of each chamber is closed with a wooden door equipped with a window and air-sampling orifice and sealed tightly to the oven liner with a rubber gasket. On occasions when no dust exposure is in progress the wooden front is replaced with a wire screen. The oven light in the upper right portion 


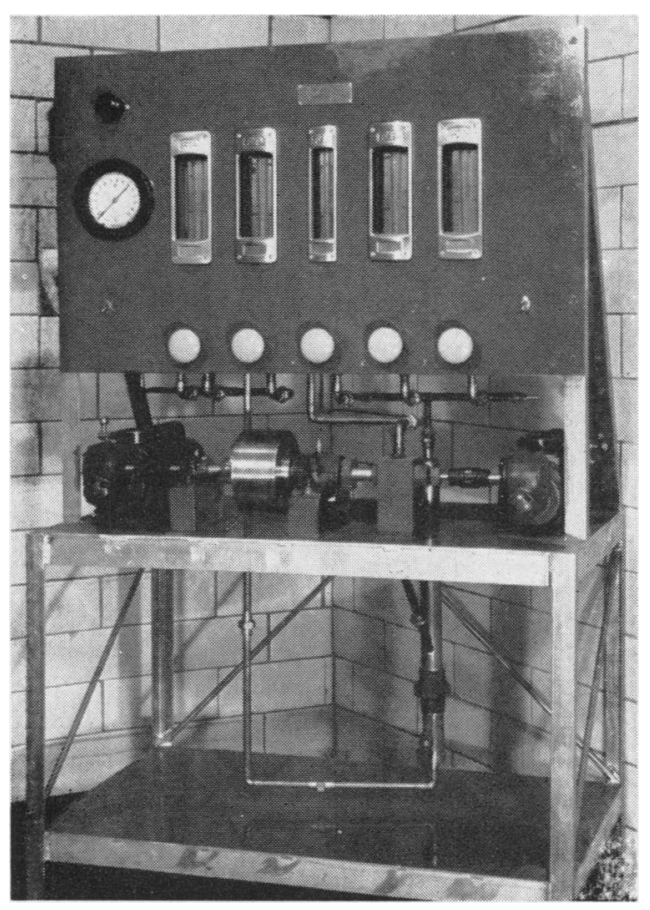

FIG. 1.-Dust dispersal machine.

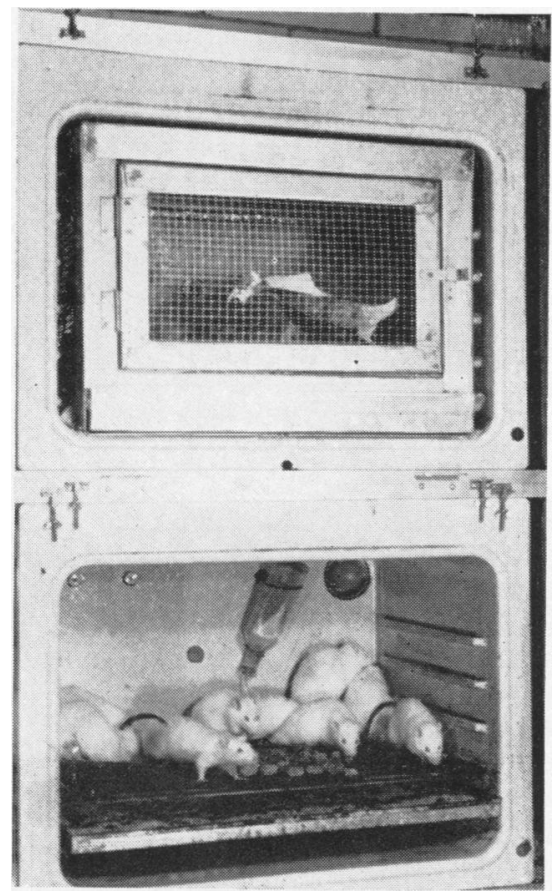

FIG. 2.-Cages with dust-tight fronts removed. provides a convenient means of observing the animals. The runners for oven shelves are suitable for wire screens to support the animals or trays to facilitate cleaning. The entire assembly can be cleaned with water, is rust-proof, can be kept free of vermin, and is gas-tight. Discharge of air during an experimental exposure is to the outside atmosphere through an electrostatic precipitator to remove dust and is facilitated by a small exhaust fan.

\section{Operation}

With the dust dispersal machine we have investigated the pulmonary effects, if any, of inhalation by pigeons, rats, hamsters, and other animals, of various metallurgical dusts found in industry and of other materials such as cobalt sulphide, nickel sulphide, and ferric sulphide. As a diluent we have used pure nickel shot, $-48+100$ mesh. This shot is sufficiently dense that it can be recovered almost quantitatively from the elutriation tube leaving the dust in a finely divided state for delivery to the exposure chambers at a uniform, controllable rate. In any event the diluent is, of course, too large to be inhaled.

Fig. 3 is a record of the dust count of air in an exposure chamber as determined with a Bausch and 2
Lomb Dust Counter when various amounts of a metallurgical dust of industry, having a particle size of about 0.2 to $0.5 \mu$ after grinding in a ball-mill for 48 hours, are mixed with $1,000 \mathrm{~g}$. of nickel shot. The dust counter was modified for use in air having a high dust count by adding to the barrel of the instrument a syringe to permit the withdrawal of

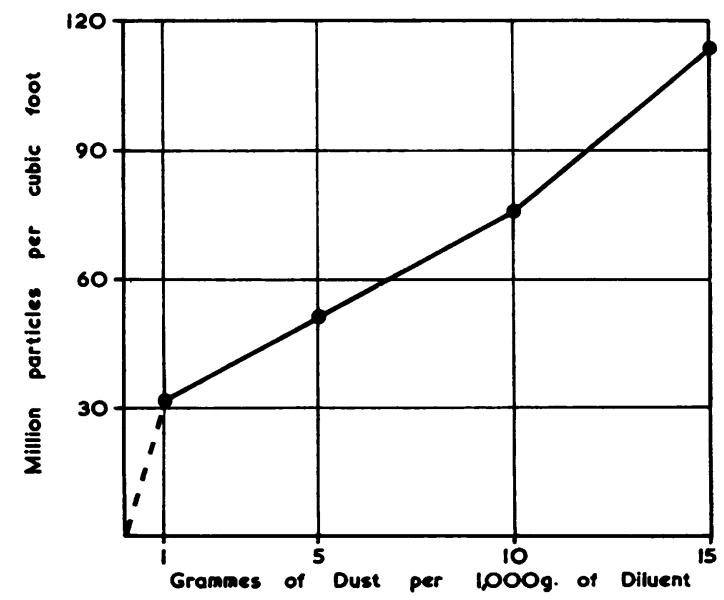

FIG. 3.-Dust counts in exposure chambers. 
TABLE 1

RANGE OF DUST COUNTS

\begin{tabular}{|c|c|c|c|c|c|c|c|c|}
\hline \multirow{2}{*}{$\begin{array}{l}\text { Sampling } \\
\text { Day }\end{array}$} & \multicolumn{2}{|c|}{ Dust 1 (m.p.p. cu. ft.) } & \multicolumn{2}{|c|}{ Dust 2 (m.p.p. cu. ft.) } & \multicolumn{2}{|c|}{ Dust 3 (m.p.p. cu. ft.) } & \multicolumn{2}{|c|}{ Dust 4 (m.p.p. cu. ft.) } \\
\hline & Range & Average & Range & Average & Range & Average & Range & Average \\
\hline $\begin{array}{l}1 \\
2 \\
3 \\
4 \\
5 \\
6 \\
7 \\
8 \\
9\end{array}$ & $\begin{array}{c}13-28 \\
21-65 \\
20-34 \\
42-48 \\
12-26 \\
61-111 \\
9-23 \\
12-24 \\
13-63\end{array}$ & $\begin{array}{l}19 \\
37 \\
24 \\
45 \\
17 \\
81 \\
15 \\
17 \\
32\end{array}$ & $\begin{array}{l}18-23 \\
17-34 \\
36-54 \\
13-24 \\
34-50 \\
16-20 \\
14-17 \\
26-39 \\
27-33\end{array}$ & $\begin{array}{l}21 \\
25 \\
45 \\
18 \\
40 \\
18 \\
16 \\
32 \\
29\end{array}$ & $\begin{array}{l}16-32 \\
14-115 \\
72-96 \\
30-71 \\
21-34 \\
64-87 \\
33-60\end{array}$ & $\begin{array}{l}21 \\
42 \\
87 \\
40 \\
28 \\
76 \\
43\end{array}$ & $\begin{array}{l}23-66 \\
39-44 \\
25-60 \\
41-52 \\
42-44\end{array}$ & $\begin{array}{l}49 \\
41 \\
42 \\
47 \\
43\end{array}$ \\
\hline
\end{tabular}

Dust 1-mixture of nickel sulphate, nickel sulphide, and nickel oxide.

Dust 2-iron sulphide. Dust 3 -cobalt sulphide. Dust 4 -nickel sulphide.

from 1.0 to $5.0 \mathrm{ml}$. of dusty air from an exposure chamber and its injection into the counting area of the instrument. For the preparation of Fig. 3 air supply to the elutriation tube was at the rate of 108 cu. ft. per hour. This rate of air supply was greatly in excess of minimum requirements for maintenance of the animals.

It is evident from Fig. 3 that, under the conditions of that experiment, dust counts in the range of 30 to 110 m.p.p. cu. ft. can be obtained by varying the ratio of dust : diluent from $1.0 \mathrm{~g}$. dust to $15 \mathrm{~g}$. dust per $1,000 \mathrm{~g}$. of nickel shot. Variation can also be produced by changing the speed of rotation of the screw which removes material from the mixing drum. It has usually been our practice to rotate the mixing drum at 12 r.p.m. and to adjust the speed of the screw so that the nickel shot from a charge containing $1,000 \mathrm{~g}$. of shot is recovered from the elutriation tube at the rate of about $142 \mathrm{~g}$. per hour over a seven-hour exposure. In other experiments the dust count was modified by changing the air supply.

The dust dispersal machine has been used with several dusts. The extent of variation in dust count among six exposure chambers (dust 1) or a smaller number of chambers (three chambers in the case of dusts 2 and 4 ; four chambers in the case of dust 3 ) is shown in Table 1. This Table shows for each of four dusts the average dust count on any day and the minimum and maximum count among all the chambers containing the dust dispersed by any one machine on that day. The determinations were made at approximately two-week intervals. The values shown for any one dust are consecutive determinations. Conditions (proportion of dust to shot, air supply, speed of screw) controlling the production of the dusty atmosphere were not the same for each of the four dusts.

Another measure of the extent of uniformity was also obtained more simply by recording the amount of shot recovered daily. On 100 consecutive days when the charge in the mixing drum contained 1,000 g. nickel shot, there were only two occasions when the quantity of shot recovered at the end of seven hours was not within the range 950 to $1,000 \mathrm{~g}$.

Thus the machine permits the production of dusty atmospheres for industrial hygiene studies and provides these atmospheres in quantities permitting the exposure of animals for periods comparable to those obtaining for workmen in industry. Unlike some other machines for producing dusty atmospheres, this one does not need to involve any alteration in the particle size or nature of the dust under investigation. Through the use of rotameters on the machine it is expected that gaseous atmospheric contaminants can also be added to the experimental atmospheres.

The authors express appreciation to The International Nickel Company of Canada Limited for financing the construction of the dust dispersal machines, to Mr. L. S. Renzoni of that Company for his design leading to its construction, and to Mr. L. Hodges, Mr. J. Horwood, and Mr. J. Slovik for other suggestions and expert technical assistance. 